\title{
An analysis of publications related to emergency medicine originating from Turkey
}

\author{
Mahmut Firat Kaynak ${ }^{1}$, Zulfi Engindeniz ${ }^{1}$, Sibel Gafurogullari ${ }^{1}$, Esra Askin Bas ${ }^{1}$, Mumin Karaali ${ }^{1}$, \\ Nizameddin Koca' ${ }^{2}$ Ismail Altintop ${ }^{3}$
}

${ }^{1}$ Department of Emergency Medicine, Sevket Yilmaz Training and Research Hospital, Bursa, Turkey

${ }^{2}$ Department of Internal Medicine, Cekirge State Hospital, Bursa, Turkey

${ }^{3}$ Department of Emergency Medicine, Kayseri Training and Research Hospital, Kayseri, Turkey

\begin{abstract}
Objective. Aim of this study was to examine the publications of the Turkish emergency medicine clinics in the journals indexed in Index Medicus between January 1st, 1994 and December 31st, 2013 thus, to demonstrate the level of scientific productivity within the 2 decades after the establishment of emergency medicine as a specialty. Method. A pubmed search was performed using "emergency medicine" and "Turkey" entries in the affiliation part and covering the dates January 11994 to December 312013. Further search was performed in the ISI web of knowledge website to find out whether the journals were indexed in SCI or SCI-Expanded lists. Number of citations were found by using Google Scholar. Publications with a first name from clinics other than emergency medicine was not included in the study. Results. 719 articles were published in 204 journals within the 20 years. $86 \%$ of the articles were originated from university hospitals. 10.6\% from research and education hospitals and 3.5\% from second level hospitals (state and private). $38.1 \%$ of the articles were prospective clinical studies, $16.8 \%$ were retrospective clinical studies, $9.2 \%$ were experimental animal studies and $7 \%$ were review articles. Studies were commonly published in Turkish Journal of Trauma and Emergency Surgery $(n=85,11.8 \%)$, American Journal of Emergency Medicine ( $\mathrm{n}=85,11.8 \%$ ), and Emergency Medicine Journal ( $\mathrm{n}=85,11.8 \%)$. Mean number of articles published annually was 35.9 articles/year. Akdeniz University published $7.5 \%$ of the articles, Dokuz Eylul University published 7.2\% and Karadeniz Technical University 4.9\% of the articles. Conclusion. Number of publications in the field emergency medicine from our country are increasing with time. Studies analyzing the quality of the publications will be guiding for the researchers.
\end{abstract}

Eur Res J 2015;1(2):55-60

Keywords: Emergency medicine in Turkey, scientific publications, references

Address for correspondence:

Mahmut Firat Kaynak, MD, Sevket Yilmaz Training and Research Hospital, Bursa, Turkey

E-mail: md_kaynak@yahoo.com

Received: 28.04.2015; Accepted: 09.06.2015: Published Online: 04.07.2015 


\section{Introduction}

Emergency medicine was officially accepted as a medical specialty in Turkey in 1993 [1]. Emergency medicine training programs were first established at university hospitals at 1994 and then established at research and education hospitals at 2006. By the end of 2013 there are a total number of 80 emergency medicine training programs, 51 at university hospitals and 29 at research and education hospitals, present in our country. Quantity and quality of the publications published in the journals indexed in international indices may be accepted as an indicator of academic progress. Studies were published analyzing emergency medicine publications and productivity in the international literature $[2,3]$. These studies were guiding the researchers for the future by analyzing the quantity and quality of the past studies. There are studies from our country analyzing scientific production of Turkish emergency medicine at different time intervals $[1,4,5]$. Our aim in this study was to demonstrate the level of scientific productivity reached by Turkish emergency medicine at the end of its second decade.

\section{Method}

After the approval of instutional ethical committee and review board, a PubMed search was performed through http://www.ncbi.nlm.nih.gov/pubmed/ internet site to identify the studies produced by Turkish emergency medicine clinics and published in journals indexed in index medicus between the dates of January 1st, 1994 and December 31st, 2013. Search was narrowed by entering "emergency medicine" and "Turkey" specifications in the affiliation tab of the PubMed website. For the manuscripts which are accepted for publication and early released online, electronic release date was considered as publication date. A further search was performed to identify whether the journals listed in the Science Citation Index Expanded (SCIE) in Thomson Reuters' 2013 list [6]. A final search was done in Google scholar to find out the number of citations each publication received.

Exclusion Criteria: Publications with a primary author from clinics other than emergency medicine were excluded from the study.

Evaluation: Publications were classified according to the type and subject of the article, name of the journal, publication date, number of citations and number of authors. Another comparison based on inclusion of the journal in the 2013 SCI-E list was also made. Analysis and descriptive statistics of data was done with "SPSS for Windows 22.0" statistical package.

Table 1. The distribution of the number of citations of articles

\begin{tabular}{lcc}
\hline Number of citation & Number & Ratio \% \\
\hline 0 & 215 & 29,9 \\
$1-5$ & 284 & 39,5 \\
$6-10$ & 112 & 15,6 \\
$11-15$ & 40 & 5,6 \\
$16-20$ & 23 & 3,2 \\
$>21$ & 45 & 6,3 \\
Total & 719 & 100,0 \\
\hline
\end{tabular}




\section{Results}

By the end of the year 2013, a total number of 719 publications were found in the journals indexed in Index Medicus that includes both of the "emergency medicine" and "Turkey" keywords. Distribution of number of publications per year has shown that there was a steady increase in number of publications per year and number of publications within the year 2013 were 129 publications corresponding $17.9 \%$ of the total. There were significant increases in the number of publications in comparison to previous years' number in the years 2002 and 2013 (Figure 1). Mean number of publications per year since the foundation of emergency medicine specialty was found to be 35.9 publications/year.

Classification of the 719 articles according to article type revealed that $38.1 \%(n=274)$ were prospective clinical studies, $35.2 \%(\mathrm{n}=253)$ were case reports, $16.8 \%(\mathrm{n}=121)$ were retrospective clinical studies, $9.1 \%(\mathrm{n}=66)$ were experimental animal studies and $0.6 \%(\mathrm{n}=5)$ were review articles (Figure 2).

The publications were classified according to main subject of the article and the 5 most common subjects of research were toxicology $22.3 \%(n=160)$, trauma $20.7 \%(n=148)$, cardiology $12.2 \%(n=88)$, general surgery $7.9 \%(n=57)$ and neurology $4.6 \%$ $(n=33)$. Distribution of the journals that the articles were published was shown in figure 3 . The articles were published in 204 different journals. The most common journals preferred for publication were Turkish Journal of Trauma and Emergency Surgery $11.8 \%(\mathrm{n}=85)$, American Journal of Emergency Medicine $11.8 \%(\mathrm{n}=85)$, and Emergency Medical Journal \%11.8 $(\mathrm{n}=85)$.

Of the 20 years of Turkish emergency medicine literature contribution, Akdeniz University got the biggest share with $7.5 \%(n=54)$, Dokuz Eylul University published $7.2 \% \quad(n=52)$ Karadeniz Technical University published $4.9 \%(n=35)$ of the manuscripts (Figure 3). 86\% $(n=618)$ of the publications were originated from university hospitals, $10.6 \%(\mathrm{n}=76)$ from research and education hospitals and $3.5 \%(n=25)$ from second level hospitals (state and public hospitals). Distribution of manuscripts according to the city of origin revealed that $15.6 \%(n=112)$ of manuscripts were from Ankara, $13.8 \%(n=119)$ from $\mathbf{E}$ mir and 7.6\% $(\mathrm{n}=55)$ from Antalya.

Articles were further classified according to the journals' indexing status in the SCI; 83.3\% $(n=599)$ of the articles were published in the journals indexed in SCI and the remaining

$16.7 \%(n=120)$ were published in the journals that were not indexed in SCI (Figure 4).

Mean number of authors per article was 5.4 and it was ranging between 1 and 17. Mean number of citations per article was 5.6 and $39.5 \%$ of the articles were cited $1-5$ times and $6.3 \%$ of the articles were cited more than 21 times (Table 1).

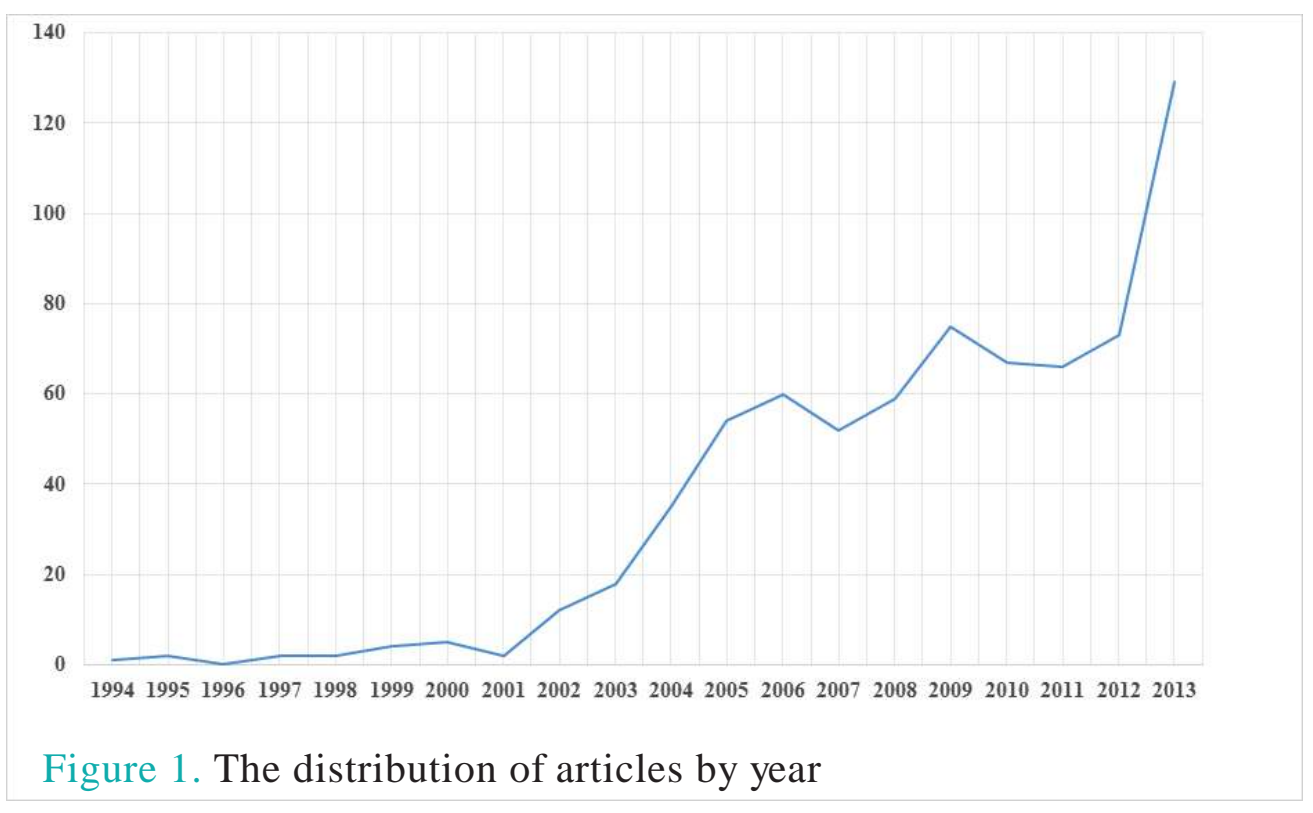




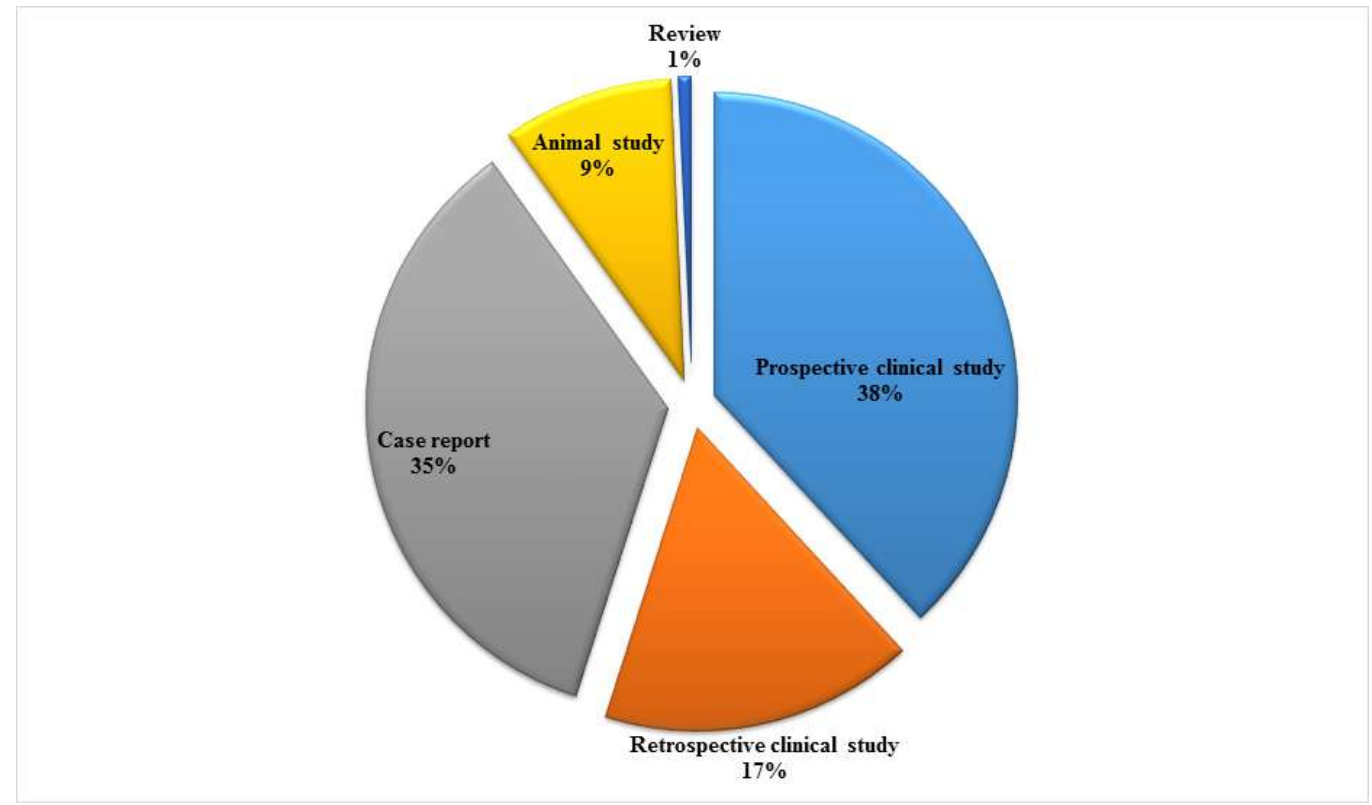

Figure 2. Distribution by the article type

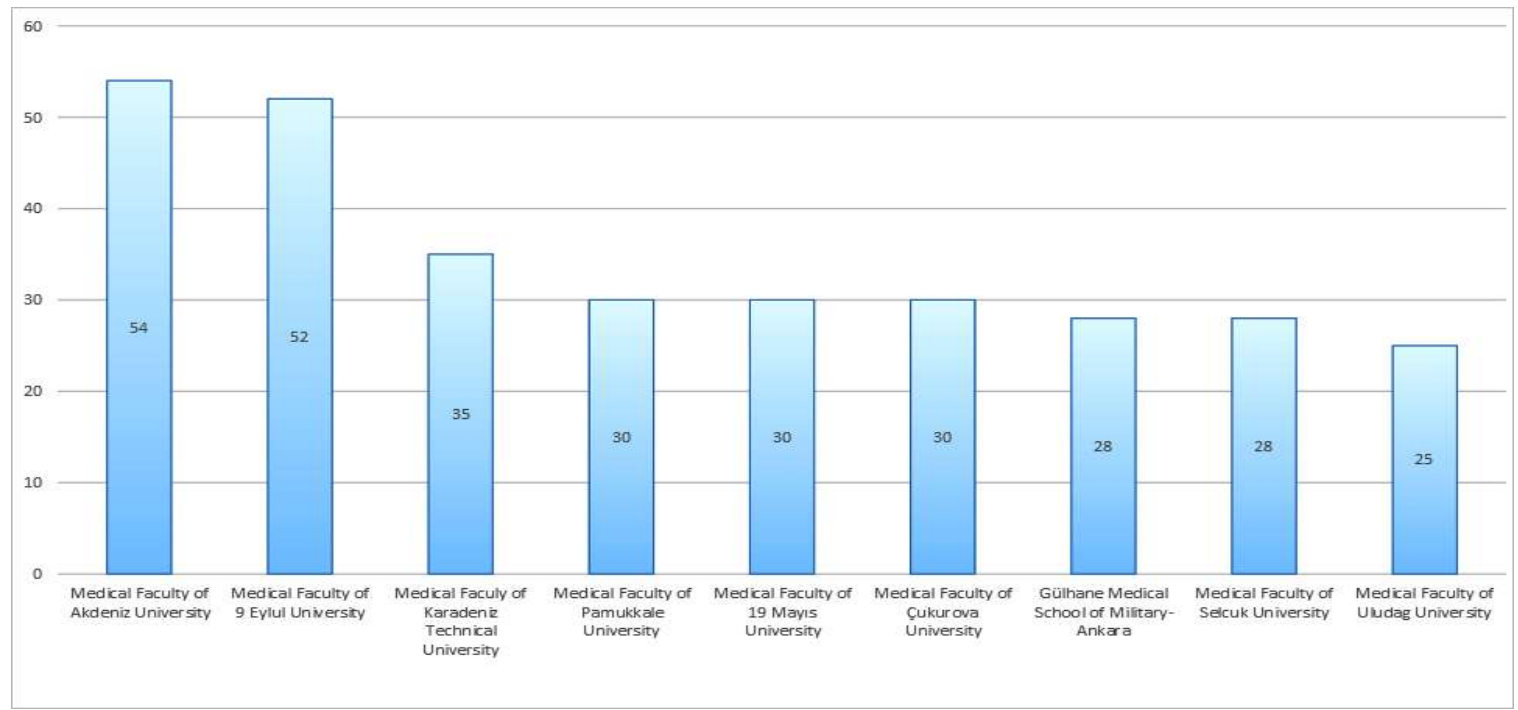

Figure 3. Article distribution according to the institution

\section{Discussion}

Turkey holds the 45 th place in the medical scientific literature ranking [7]. Publications originating from Turkey in the areas of pediatrics, medical ethics, urology, neuro-imaging and earnose-throat are quantitatively placed in the top ten countries. Since 2001 articles published in the journals indexed in SCI and SCI-E were being used as a criteria for academic advancement in our country. After that, number of the articles published in the journals indexed in SCI and SCI-E increased significantly.

By the end of the second decade of the emergency medicine as a specialty in Turkey, its contribution to international literature is progressively increasing. In the field of emergency medicine, overall mean number of publications from Turkey per year was 35.9 publications/year and for the last 10 years it increased to 63.5 publications/year. This could be accepted as an indication of continuing increase in scientific productivity. Furthermore, just the number 


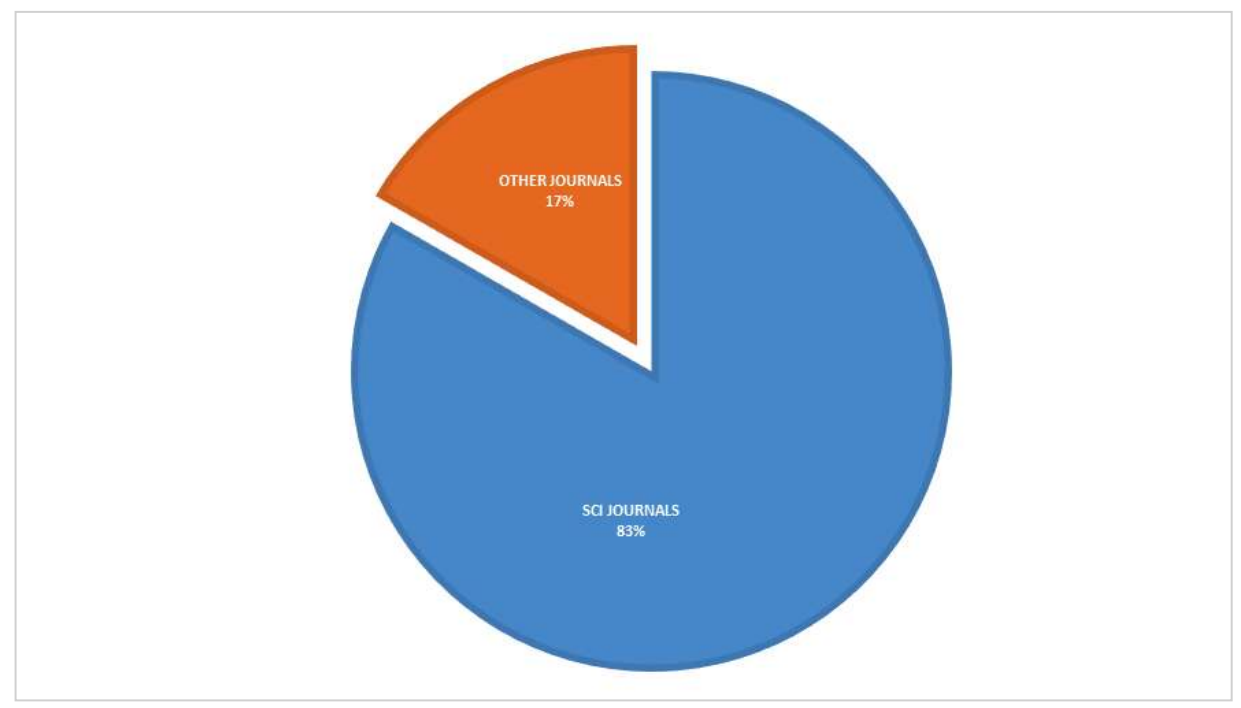

Figure 4. The distribution according to published journals

of articles published in 2013 constitutes the $17.9 \%$ of the total number, supporting the increasing trend in scientific productivity. A 2011 study by Cinar et al draws attention to a similar increase stating that $77 \%$ of the publications were from the last five years (2006 - 2011) [1]. Yanturali et al evaluated the first decade of emergency medicine in a 2004 study and found that the $76 \%$ of the publications were from the last three years (2000-2003) [4]. These results are similar to our results and supporting an increasing trend in terms of number of publications.

Total number of worldwide publications in emergency medicine field between 1996 - 2005 years was reported to be 14605 . United States of America published 8550 (58.54\%) of this. 1222 $(8.37 \%)$ of publications originated from United Kingdom and 663 (4.54\%) from Japan [8]. Turkey's share of emergency medicine literature could not yet reach the level it ought to be. Previous studies' prediction that our contribution to emergency medicine literature will increase in the forthcoming years have been come true and it seems that increase is continuing.

A recently published report by Web of Science reported that although relative impact factor (IF) of Turkey was rising it is still only half of the world average [9]. Most commonly used parameters for scientific research quantity and quality were number of publications in SCI and IF, respectively. During the first decade of emergency medicine in Turkey, $48.8 \%$ of the articles were published in journals indexed in SCI [10]. Furthermore, Ersel et al studied first 15 years of Turkish emergency medicine and reported that $88.4 \%$ of the articles were published in SCI journals [4]. In our study, we found that, within the 20 years, $83 \%$ of the articles were published in SCI journals. This data supports that Turkey's contribution to emergency medicine literature increasing not only quantitatively but also qualitatively. Furthermore, another quality indicator evaluated in our study was number of citations and mean number of citations per article was 5.6 at the time of our study. As the number of publications raised at the last years of the study period it may be speculated that the number of citations will increase in the years ahead.

Number of citations may vary according to journal and type of the article. Distribution of the articles among journals revealed that publications were concentrated on certain journals; Turkish Journal of Trauma and Emergency Surgery, American Journal of Emergency Medicine, and Emergency Medical Journal $[1,4,10]$. On the other hand, number of publications in the emergency medicine journals with high IF value still remains low. A 2009 article reported that Turkey's ranking in terms of number of publications from emergency medicine clinics was 16, however, in terms of IF, Turkeys ranking declined to 42 among 45 countries [7]. This problem of publication quality was not specific to emergency medicine. It is a common problem among all scientific fields and it can mainly be attributable to scarcity of the resources devoted for scientific research. 
We found that $54.9 \%$ of the articles were original research and $35.2 \%$ were case reports. Previous studies have reported similar proportions $[1,4,10]$. Animal experiments constitutes $9.1 \%$ of the articles in our study. A 2013 study by Cinar et al reported animal experiment rate as 7\% [1]. Another recent study examined the publications of emergency medicine academicians' in the area of trauma and reported animal experiment rate as $11 \%$ [5]. Our study reported similar rates and rising trend in ratio of animal experiments is hopeful for the future quality of publications.

Yanturali et al. [10] reported that the most common areas of research were trauma (34.5\%), toxicology $(21.4 \%)$ and cardiology (9.5\%). Another study reported that the main areas of research were toxicology and environmental emergencies (32.9\%), followed by trauma (15.9\%) and pharmacology and biological markers (11.9\%) [4]. Similarly, we found that the main areas of research were toxicology, trauma and cardiology.

Ranking of emergency medicine clinics in terms number of publications revealed that Akdeniz University was the first with $7.5 \%, 9$ Eylul University was second with $7.2 \%$ and Karadeniz Technical University was third with $4.9 \%$ of the total publications. These results may be explained as these clinics are the oldest clinics in Turkey with well-established organization and sufficient academic staff.

Institution based distribution of publications shown that majority of the articles $(86 \%)$ are from university hospitals. This is mainly due to that university hospitals were the single academic source in field of emergency medicine until 2006 in which the first residency programs were started at research and education hospitals. Within the 7 years after that, research and education hospitals produced $10.6 \%$ of the articles. A further $3.5 \%$ was from second level hospitals.

Furthermore, distribution of the publications according to cities revealed that of the articles were from Izmir and Ankara. 2008 TUBITAK report have shown that $35 \%$ of the publications from turkey were from Ankara followed by Istanbul with $22 \%$ and Izmir with 7\% [11]. This is an indicator of uneven distribution of academic resources across our country. Future corrective policies should be designed to improve this heterogenic distribution. Only 'PubMed' database was used for our study and publications that were not indexed in PubMed were out of evaluation, this is the main limitation of our study.

In conclusion, Turkey's contribution to emergency medicine literature is increasing quantitatively. To increase quality publication certain measures should be taken such as targeting journals indexed in SCI with higher IF values, planning high quality original research, animal and laboratory studies could be effective. Education, support and encouragement of the residents for scientific research will further increase quantity and quality of publications. Studies like this may enlighten us about our level of academic advancement and may guide us for the future.

\section{References}

[1] Cinar O, Dokur M, Tezel O, Arziman I, Acar YA. Contribution of Turkish Emergency Medicine to the international literature: evaluation of 15 years, Ulus Travma Acil Cerrahi Derg. 2011;17 (3):248-252

[2] Orer HS. Turkiye'nin Bilimsel Yayin Performansi, Ankem Derg. 2011;25(Ek 2):134-138

[3] Rosenzweig JS, Van Deusen SK, Okpara O, Datillo PA, Briggs WM, Birkhahn RH. Authorship, collaboration, and predictors of extramural funding in the emergency medicine literature. Am J Emerg Med. 2008;26:5-9.

[4] Ersel M, Yuruktumen A, Ozsarac M, Kiyan S, Aksay E. Turkiye'deki Acil Tip Anabilim Dallari'nin uluslararasi yayin uretimi: 15. Yil degerlendirmesi. Turk J Emerg Med. 2010;10:55-60. [5] Dogan NO. Evaluation of international scientific publications and citations on trauma authored by professors and associate professors of emergency medicine in Turkey, Turkiye Acil Tip Dergisi. 2013;13(2):64-68

[6] Levsky ME, Rosin A, Coon TP, EnslowWL, Miller MA. A Descriptive Analysis of Authorship Within Medical Journals. 19952005. South Med J. 2007;100:371-375

[7] Demirel IH, Sarac C, Akilli E, Buyukcinar O, Yetgin S, Gurses EA. Turkiye Universitelerinin Bilimsel Yayin Performansi II 19812007, TUBITAK-ULAKBIM, Ankara (2009).

[8] Wilson MP, Itagaki MW. Characteristis and trends of published emergency medicine research. Acad Emerg Med. 2007;14:635-40. [9] Thomson Reuters, Master JournalList. http://ip-science. Thomsonreuters.com/mjl/ [Access date: 26 March 2013]. [10] Yanturali S, Aksay E, Cevik AA. International Publications from Turkish Emergency Medicine Departments: analysis of first ten years. Turk J Emerg Med 2004;4:170-3

[11] Demirel IH, Sarac C, Akilli E, Büyükcinar O, Yetgin S Gürses EA. Turkiye'nin Bilimsel Yayin Haritasi, TUBITAK-ULAKBIM, Ankara (2007) 